\title{
Modification of Bituminous Mixture using Polyethylene Granules
}

\author{
Shahreena Melati Rhasbudin Shah, Nor Izzah Zainuddin, Yee Hooi Min, Li-Sian Tey
}

\begin{abstract}
Pavement performance is generally influenced by traffic, moisture, and quality of construction and maintenance. Deterioration on road surface can develop due to one or combination of these factors. In order to improve pavement performance, the modification of bituminous mixture for road surface can be achieved by adding additives or modifiers in the mix. This study presents the utilization of two types of polyethylene (PE): high density polyethylene (HDPE) and low density polyethylene (LDPE), a plastic waste products as an additive to enhance the properties of bituminous mixture. PE has been extensively used in industrial and domestic applications due to its low-cost, lightweight and durable properties. Wearing course samples of control and modified mixes were prepared using Marshall mix design method and according to Standard Specification for Road Works as guidelines. Three types of HDPE/LDPE blends with ratios of 75/25, 50/50 and 25/75 have been prepared and tested. It was found that polyethylene modified bituminous mixes show significant increment in Marshall stability and lower optimum bitumen content (OBC) in comparison to unmodified mix, where equal blend of HDPE/LDPE (50/50) shows a better Marshall properties. This shows that an addition of polyethylene in bituminous mix can withstand higher traffic loading with lower bitumen content.
\end{abstract}

Keywords : HDPE/LDPE blends, marshall properties, modified bituminous mixture, polyethylene

\section{INTRODUCTION}

Flexible roads surfaces are made of aggregate, bitumen and filler, commonly referred as bituminous mixture. Increase in number of heavy vehicles traffic, harsh environmental conditions, improper design and maintenance can caused deterioration to the road surface and resulted in short serviceability of pavement. The performance of pavement can be improved by modifying bituminous mixtures. This can be achieved by incorporating additives in the mix for instance reclaimed rubber, latex, and polymer.

Due to its low-cost, lightweight and durable properties, plastics are extensively used in industrial and domestic

Revised Manuscript Received on October 22, 2019.

* Correspondence Author

Shahreena Melati Rhasbudin Shah*, Faculty of Civil Engineering, Universiti Teknologi MARA, Cawangan Pulau Pinang, Kampus Permatang Pauh, 13500 Permatang Pauh, Pulau Pinang, Malaysia. Email: shahr129@uitm.edu.my

Nor Izzah Zainuddin, Faculty of Civil Engineering, Universiti Teknologi MARA, 40450 Shah Alam, Selangor, Malaysia. Email: norizzah@uitm.edu.my

Yee Hooi Min, Faculty of Civil Engineering, Universiti Teknologi MARA, Cawangan Pulau Pinang, Kampus Permatang Pauh, 13500 Permatang Pauh, Pulau Pinang, Malaysia. Email: minyh@uitm.edu.my

Li-Sian Tey, Faculty of Civil Engineering, Universiti Teknologi MARA, Cawangan Pulau Pinang, Kampus Permatang Pauh, 13500 Permatang Pauh, Pulau Pinang, Malaysia. Email: 1stey@uitm.edu.my applications. However, plastics waste is a non-biodegradable and its disposal cause a serious environmental issue. Several studies have attempted to utilize plastic waste in bituminous mixture to increase the performance and strength of a pavement [1]-[5]. [5] studied on waste PVC in bituminous mixes indicate a stronger bond between the aggregate and the bitumen with an addition of waste PVC, hence increase the mix stability. In addition, the tensile strength ratio which determines the moisture susceptibility of the mixes also increase. Modified mixes also provide better resistance to permanent deformation where observed rut depth is much lower than control mix. [4] found that the bleeding of pavement surface decreases in hot weather condition since polymer modified bitumen can withstand higher temperature and the optimum content of plastic waste to be used is range between 5\% and 10\%. [1] and [3] found that the Marshall stability obtained for modified mixes are higher compared to control mix.

However, plastic waste for example plastic bags and plastic bottles must undergoes several processes namely segregation, cleaning and shredding. Polyethylene (PE) granules is a commercially available plastic waste product that are ready to be incorporated into bituminous mixtures without undergoes all the exhausting process. Two types of PE: high density polyethylene (HDPE) and low density polyethylene (LDPE) are widely used in industrial for packaging food and beverages. These materials have different properties. HDPE is stronger, rigid and can withstand higher temperature, and commonly used for milk cartons, laundry detergent bottles, garbage bins, and cutting boards. While LDPE is softer but more flexible, typically used for grocery bags, milk carton lining and cling film. Due to different characteristics and advantages of HDPE and LDPE, and limited studies on utilization of both materials, this paper utilized granules form of HDPE/LDPE blends as an additive to enhance the properties of bituminous mixture.

Two different processes can be used to incorporate additive in bituminous mixture: dry or wet process. For dry process, the additive was blended with the aggregates prior mixing it with bitumen. Whereas in wet process, additive is mixed with the bitumen, and the resulted modified binder then added to the aggregates. Majority of studies used wet process to analyse the effects of PE in bitumen [6]-[11]. However, wet process limits the usage of plastic waste. [12] suggested that the optimum value of PE content is $3 \%$ by weight of bitumen, which improved the rutting resistance within the workability limit. An amount higher than 
$6 \%$ was not feasible due to the high viscosity of the binder. Thus, to increase the amount of PE incorporated in the mix, this study adopted dry process and Marshall mix design method to prepare the bituminous mixture. Unlike wet process, dry process did not change the bitumen properties, therefore allows a higher PE content. The addition of PE to the aggregate will fill the pores and coats the aggregates surface, hence reduce the absorption of water.

The objectives of this study are to

a) evaluate the Marshall properties of bituminous mixtures modified with HDPE/LDPE blends

b) determine the optimum ratio of HDPE/LDPE blends which satisfies JKR specifications

\section{METHODS}

This study consist on laboratory works divided into three stages. The first stage was the preparation of materials, namely aggregate and bitumen. Several tests have been performed on the aggregate and bitumen. All properties conform to Standard Specification for Road Works [13]. Second stage involves a preparation of asphaltic concrete wearing course as a laboratory specimen. Wearing course is the upper layer of road surface. The properties of unmodified (control) and modified mixes were obtained and analysed. From the analysis, optimum bitumen content (OBC) for both type of mixture can be determined. In the third stage, bulk specific gravity, Marshall stability and flow were performed on the control and modified mixes samples designed at OBC. The Marshall properties were evaluated and compared with Jabatan Kerja Raya (JKR) specification. The experimental flow of the laboratory works is shown in Fig. 1.

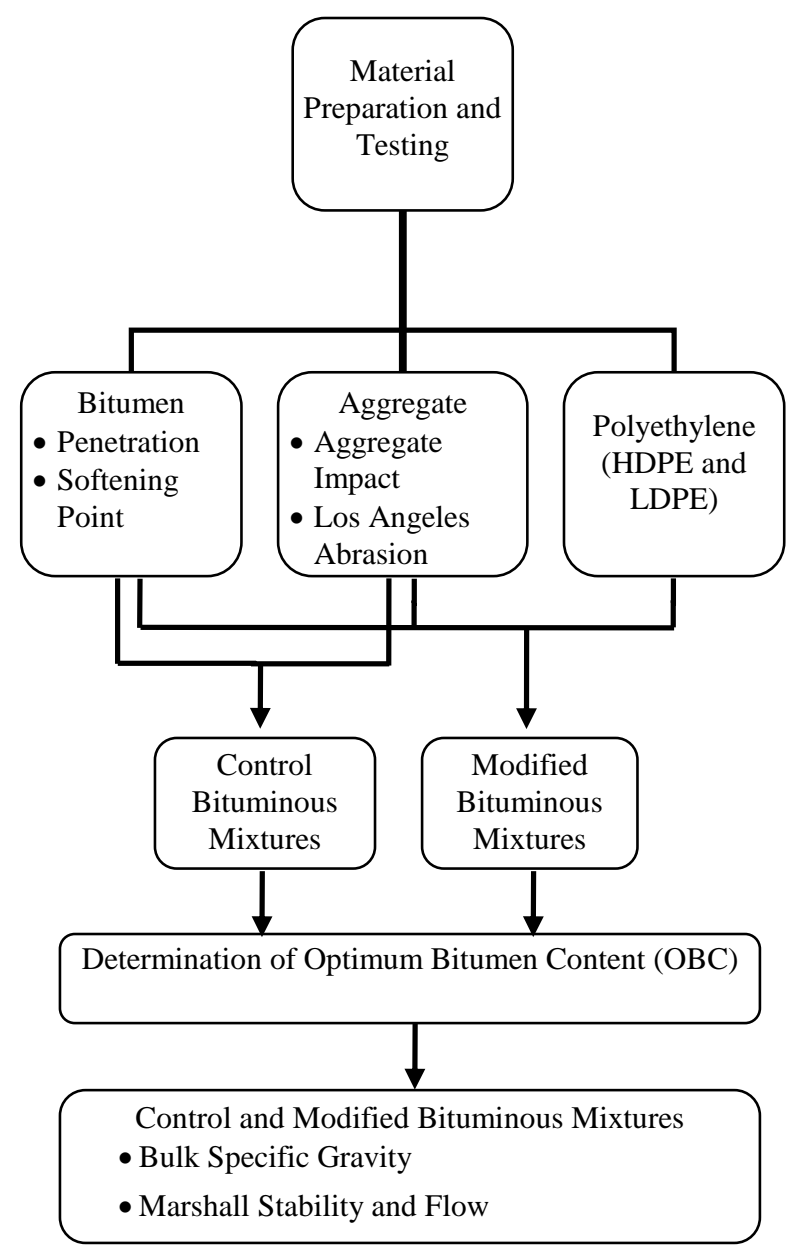

\section{A. Materials}

The materials used for bituminous mixes preparation were bitumen, aggregate, filler and polyethylene. Bitumen penetration grade $80 / 100$ was used as a binder. Laboratory tests were conducted on the bitumen sample namely penetration and softening point test. The aggregates were crushed granite obtained from local quarry. Aggregates were subjected to aggregate impact and abrasion test. Ordinary Portland Cement (OPC) was used as filler. Two types of PE were used as additives, high density polyethylene (HDPE) and low density polyethylene (LDPE), supplied by Lim Seng Plastic, Perak. Both PE are in granular shape range from 3 to 5 $\mathrm{mm}$ and were blend at a ratio given in Table I. Based on Table $\mathrm{I}$, the PE content incorporated in the mixture are $2 \%$ by weight of aggregate. This is suggested by [14] where maximum value of PE can be added in bituminous mixtures is not more than 2\% without compromising the Marshall properties required by JKR specifications. Properties of bitumen and aggregates are presented in Table II and Table III, respectively.

Table- I: Percentage of HDPE/LDPE blends

\begin{tabular}{|c|c|c|c|}
\hline \multirow{2}{*}{ Ratio } & \multicolumn{3}{|c|}{ Polyethylene } \\
\cline { 2 - 3 } & HDPE (\%) & LDPE (\%) & $\begin{array}{c}\text { HDPE/LDPE } \\
\text { blend (\%) }\end{array}$ \\
\hline $75 / 25$ & 1.5 & 0.5 & \\
\hline $50 / 50$ & 1.0 & 1.0 & \multirow{2}{*}{2.0} \\
\hline $25 / 75$ & 0.5 & 1.5 & \\
\hline
\end{tabular}

Table- II: Properties of bitumen

\begin{tabular}{|c|c|}
\hline Properties & Value \\
\hline Penetration $(\mathrm{PEN})$ & 85 \\
\hline Softening point $\left({ }^{\circ} \mathrm{C}\right)$ & 46 \\
\hline Specific gravity & 1.02 \\
\hline
\end{tabular}

Table- III: Properties of aggregate

\begin{tabular}{|c|c|}
\hline Properties & Value \\
\hline Aggregate Impact (\%) & 26 \\
\hline Aggregate Abrasion (\%) & 24 \\
\hline Bulk specific gravity & 2.67 \\
\hline
\end{tabular}

\section{B. Marshall Mix Design Method}

Control and modified mixes were prepared using Marshall mix design method. The two main features of Marshall mix design are density-voids analysis and stability-flow tests. Marshall stability indicates the maximum load that can be sustained by the sample at $60^{\circ} \mathrm{C}$ while the flow indicates the deformation or movement of the sample at the maximum load. These properties able to anticipate the performance of the mix such as stability, load carrying capability and resistance to permanent deformation. This method also can determine optimum bitumen content.

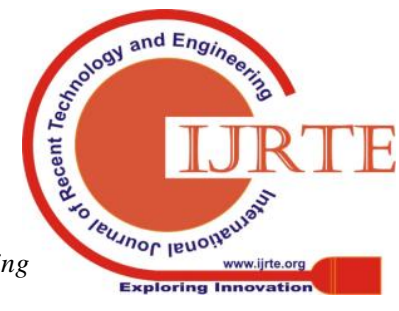


Bitumen content of $4.0-6.0 \%$ (in $0.5 \%$ increments) were designed for asphaltic concrete wearing (ACW 14) preparation.

The modified mixes were prepared using dry process. HDPE/LDPE blends were mixed with the aggregates during aggregate heating process $\left(150-180^{\circ} \mathrm{C}\right)$ to allows the additive fully liquify and create a thin film on the aggregate surface. Then, preheated bitumen was added to the HDPE/LDPE coated aggregates. Mixes with $0 \%$ additive also were prepared as control sample. Each test sample approximately weight 1200 grams, subjected to a laboratory compaction of 75 blows on each face.

The compacted bituminous samples then were subjected to laboratory tests to assess the properties of control and HDPE/LDPE modified bituminous mixtures. Bulk specific gravity determination in accordance with ASTM D 2726 [15] were conducted on each of compacted samples. The results were used for density - voids analysis: voids in aggregate filled with bitumen (VFB) and air voids in mix (VIM). The compacted bituminous mixtures samples also were tested for Marshall stability and flow as per ASTM D 1559 [15].

High flow value indicates the potential of permanent deformation, meanwhile low flow value is not desirable as the bituminous mixture might have insufficient binder, which may lead to durability problems. Mixes with high stability but low flow value are also not desirable as the mixes can cracks under heavy traffic loads. Mix stiffness can be computed from stability and flow value. Higher stiffness value indicates that a stiffer pavement which can help to resist permanent deformation. Higher air voids in mix can create pathways for air and water. In contrast, low air voids can cause bleeding of the pavement due to insufficient voids space to accommodate the expansion of binder in warm weather. A specified range of VFB in the compacted mixture is required to ensure sufficient bitumen to provide durability and to sustain traffic loads.

The determination of OBC was carried out by averaging five bitumen content corresponding to: [13].

a) maximum stability,

b) $3 \mathrm{~mm}$ flow,

c) maximum specific gravity,

d) $4.0 \%$ VIM, and

e) $75 \%$ VFB

Subsequently, three (3) samples at optimum bitumen content for control and modified bituminous mixtures were prepared, tested and analysed again with the previous lab works procedure to compare their properties with standard requirement in accordance with JKR Standard Specification for Road Works [13].

\section{RESULT AND DISCUSSION}

\section{A. Properties of Control and Modified Bituminous Mixtures}

The volumetric properties, Marshall stability and flow were analysed for control and HDPE/LDPE modified bituminous mixtures. Based on the results, the utilization of HDPE/LDPE blends as additives demonstrates an increment in the Marshall stability of the bituminous mixtures. The stability of all modified bituminous mixtures at bitumen content range from $4.0-6.0 \%$ are significantly higher than unmodified mix. The maximum stability attains at 5\% bitumen for $25 \mathrm{HDPE} / 75$ LDPE blend was $28200 \mathrm{~N}$, whereas control mix at the same amount of bitumen yields a maximum stability of $13000 \mathrm{~N}$ Mix with 50/50 blend requires lowest bitumen content which is $4.8 \%$ at maximum stability of $20100 \mathrm{~N}$. However, a blend with ratio $75 / 25$ needs a much higher bitumen content to achieve maximum stability, which is not desirable. This proves that by utilized a suitable HDPE/LDPE blend increases the strength of bituminous mixture which in turns can withstand a higher traffic loading, at a lower bitumen content.

Modified mixes in other hand require a higher bitumen content to achieve $3 \mathrm{~mm}$ flow. The flow value typically increases with bitumen content. Incorporating $\mathrm{PE}$ in bituminous mix especially HDPE can make the mix became stiffer and less flexible, therefore a higher content of bitumen is needed to achieve desirable flow value. Analysis on voids namely VIM and VFB shows lower bitumen content requires to achieve the specified properties compared to control mix.

From the analysis, bitumen content which corresponding each parameter specified by [13] were then averaged to determine OBC (Table IV). The OBC values for control mix were $5.18 \%$. As for modified mixes, the $\mathrm{OBC}$ values obtained were $5.30,4.88$, and $5.00 \%$ for $75 / 25,50 / 50$ and $25 / 75$ HDPE/LDPE blends, respectively. Since HDPE is harder compared to LDPE, a higher content in blend might not fill the aggregate pores at maximum. In comparison, blends with $50 / 50$ and 25/75 exhibits lower OBC due to the coating of HDPE/LDPE on the surface of aggregates might fill the aggregate pores, thus limits the amount of bitumen absorbs into the pores. Hence, requires a less bitumen content.

\section{B. Optimum HDPE/LDPE Blend}

As indicates in Table $\mathrm{V}$, mixes modified with HDPE/LDPE has nearly twice the Marshall stability compared to unmodified sample. This suggest that the modified mix is stronger than a conventional mix. It might be due to the coating of HDPE/LDPE on the aggregate surface which gives a better bonding, thus increase the strength of the mixes. The JKR Standard Specification for Road Works [13] allows a flow value in the range of 2.0 to $4.0 \mathrm{~mm}$. The flow value for most of modified samples are higher than control sample and within the allowable range. The mix stiffness computed using Marshall stability and flow increased with the addition of HDPE/LDPE.

VIM obtained for all samples are within the allowable value specified in JKR Standard Specification for Road Works. As for VFB, the value for modified mixes is higher than control mix and within the specified range except for 25/75 modified bituminous mixes. From Table V, HDPE/LDPE blend with ratio of 50/50 provides better Marshall properties which satisfies all the test parameter as JKR requirement and requires lower bitumen content. Blend with $75 \mathrm{HDPE} / 25 \mathrm{LDPE}$ also meets all the requirement however is not desirable due to higher content of bitumen. 
This in turn will add an extra cost in pavement materials. Modified mixes with $25 / 75$ blend provide a higher stability value compared to others and lower bitumen content than control mix but did not meet the VFB parameter as requires

by JKR Standard Specification for Road Works [13].

Table- IV: Determination of optimum bitumen content

\begin{tabular}{|l|c|c|c|c|}
\hline \multicolumn{2}{|c|}{ Properties } & \multirow{2}{*}{ Control } & \multicolumn{3}{c|}{ Modified HDPE/LDPE } \\
\cline { 4 - 5 } & & $75 / 25$ & $50 / 50$ & $25 / 75$ \\
\hline Maximum stability, N & 5.0 & 5.5 & 4.8 & 5.0 \\
\hline 3 mm flow & 4.4 & 5.8 & 4.4 & 4.9 \\
\hline Maximum specific gravity & 5.6 & 5.2 & 5.4 & 5.2 \\
\hline $4 \%$ VIM & 5.4 & 5.2 & 5.1 & 5.1 \\
\hline
\end{tabular}

\begin{tabular}{|c|c|c|c|c|c|}
\hline \multirow{2}{*}{ Properties } & \multirow{2}{*}{ JKR Requirement } & \multirow{2}{*}{ Control } & \multicolumn{3}{|c|}{ Modified HDPE/LDPE } \\
\hline & & & $75 / 25$ & $50 / 50$ & $25 / 75$ \\
\hline Stability, S (N) & $>8000$ & 12726 & 25616 & 23654 & 28499 \\
\hline Flow, F (mm) & $2.0-4.0$ & 3.3 & 3.5 & 4.0 & 3.3 \\
\hline Stiffness (N/mm) & $>2000$ & 3856 & 7319 & 5914 & 8636 \\
\hline $\mathrm{OBC}(\%)$ & $4.0-6.0$ & 5.18 & 5.3 & 4.88 & 5.0 \\
\hline Air voids in mix, VIM (\%) & $3.0-5.0$ & 4.4 & 4.6 & 3.6 & 3.5 \\
\hline $\begin{array}{l}\text { Voids in aggregate filled with } \\
\text { bitumen, VFB }(\%)\end{array}$ & $70-80$ & 72.9 & 78.9 & 76.2 & 86.7 \\
\hline \multicolumn{2}{|l|}{$75 \%$ VFB } & 4.8 & \multicolumn{2}{|c|}{4.7} & 4.8 \\
\hline Average Bitumen Content (\%) & 5.18 & 5.3 & \multicolumn{2}{|c|}{4.88} & 5.0 \\
\hline
\end{tabular}

Table- V: Properties of Marshall mix design for control and modified mixes

\section{CONCLUSION}

It can be concluded that HDPE/LDPE blend can improves the properties of the bituminous mixtures. The strength of the mixes increased significantly with the addition of HDPE/LDPE blends, thus improve load carrying capability. The ratios of HDPE/LDPE blend influence the properties of bituminous mixtures. Higher HDPE content is not desirable due to higher optimum bitumen content. Whereas higher LDPE leads to a higher void in aggregate filled with bitumen that does not satisfies with the JKR requirement. Modified mix with equal blend of HDPE/LDPE (50/50) shows a better Marshall properties and requires a lower bitumen content.

\section{ACKNOWLEDGMENT}

Grateful acknowledgment is made to Universiti Teknologi MARA, Cawangan Pulau Pinang for the support provided in funding and facilities. The authors also like to thank the Kuad Quarry Sdn Bhd and Lim Seng Plastic for the materials provided. The authors would like to express special thanks to Jesin Construction Sdn. Bhd. for the grant provided of RM2800 from 16 January 2018 to 15 July 2019. The authors also wish to thank Nur Airin Che Mohamad Zoidin and Nur Ain Izzati Nasaruddin for their contribution in collection, extraction and analysis of the data.

\section{REFERENCES}

1. S. Bansal, A. K. Misra, P. Bajpai, "Evaluation of modified bituminous concrete mix developed using rubber and plastic waste materials," in International Journal of Sustainable Built Environment, 6, 2017, pp. 442-448.
2. A. P. Patil, S. S. Yeole, M. V. Nilakanth, M. Tanpure, "Use of plastic waste in bituminous road," International Journal for Research in Applied Science \& Engineering Technology (IJRASET), 5(5), 2017, pp. 557- 560.

3. A. Shaikh, N. Khan, F. Shah, D. Shukla, G. Kale, "Use of plastic waste in road construction," International Journal of Advance Research and Development, 2(5), 2017, pp. 14 - 19.

4. A. Vamshi, "Use of waste plastic in construction of bituminous road," International Journal for Technological Research in Engineering, 2(9), 2015, pp. 2205-2208.

5. A. Behl, G. Sharma, G. Kumar, "A sustainable approach: utilization of waste PVC in asphalting of roads," Construction and Building Materials 54, 2014, pp. 113-117.

6. A. M. Abd-Allah, M. I. E. Attia, M. F. A. Khamis, E. M. M. Deef-Allah, "Effect of using polymers on bituminous mixtures characteristics in Egypt," Journal of Mechanical and Civil Engineering, 11(4), 2014, pp. 54-63.

7. T. Ali, N. Iqbal, M. Ali, K. Shahzada, "Sustainability assessment of bitumen with polyethylene as polymer," Journal of Mechanical and Civil Engineering, 10(5), 2014, pp. 01-06.

8. N. Z. Habib, I. Kamaruddin, M. Napiah, I. M. Tan, "Rheological properties of polyethylene and polypropylene modified bitumen," International Journal of Civil and Environmental Engineering, 3(2), 2011, pp. 96-100.

9. V. S., Punith, A. Veeraragavan, "Behavior of reclaimed polyethylene modified asphalt cement for paving purposes," Journal of Materials in Civil Engineering, 23(6), 2011, pp. 833-845. Available: doi:10.1061/(ASCE)MT.1943-5533.0000235.

10. A. M. Othman, "Effect of low-density polyethylene on fracture toughness of asphalt concrete mixtures," Journal of Materials in Civil Engineering, 22(10), 2010, pp. 951-967.

11. S. Hinıslıoğlu, E. Ağar, "Use of waste high density polyethylene as bitumen modifier in asphalt concrete mix," Materials Letters, 58(3-4), 2004, pp. 267-271.

12. K. A. Ghuzlan, G. G. Al-Khateeb, Y. Qasem, "Rheological properties of polyethylene-modified asphalt binder," Athens Journal of Technology \& Engineering, $\mathrm{X}(\mathrm{Y})$, 2011, pp. 1-14. 
13. Public Work Department, Standard Specification for Road Works. JKR/SPJ/S4-2008, Kuala Lumpur, 2008.

14. S. M. R. Shah, N. I. Zainuddin, Y. H. Min, N. A. I. Nasaruddin, T. L. Sian, "Reduction of optimum bitumen content in polyethylene modified bituminous mixes," American Journal of Civil Engineering, 6(3), 2018, pp. 93-98. Available: doi:10.11648/j.ajce.20180603.12

15. American Society for Testing and Materials. Pavement Management Technologies, Road and Paving Materials, 04.03, Philadelphia, 2014.

\section{AUTHORS PROFILE}

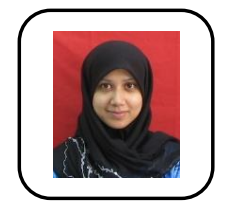

Shahreena Melati Rhasbudin Shah is a Senior Lecturer in the Faculty of Civil Engineering at the Universiti Teknologi MARA, Cawangan Pulau Pinang. She graduated with master's degree in civil engineering (Transportation and Highway) in 2006 from University Teknologi Malaysia. She has published papers in conference proceedings and respectable journals. Her research interests include pavement materials, traffic flow, driver behavior, and transportation engineering. She has obtained 12 awards in Invention, Innovation and Design competition. She has a professional relationship as a graduate engineer in Board of Engineer Malaysia (BEM).

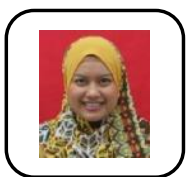

Nor Izzah Zainuddin is a Senior Lecturer in the Faculty of Civil Engineering, Universiti Teknologi MARA, Shah Alam. She obtained her diploma, Bachelor's degree and master's degree in Civil Engineering from Universiti Teknologi MARA (UiTM), Malaysia in 2007, 2010 and 2013 respectively. She has been serving UiTM since May 2013. Her research interest includes Highway and Transportation Engineering, Pavement Engineering, Traffic Engineering, Road Safety and Railway Engineering.

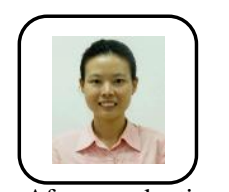

Yee Hooi Min graduated with a doctorate degree Structural Engineering, Master of Science Engineering and Bachelor of Engineering (Honours) Civil Engineering from the Universiti Sains Malaysia, Pulau Pinang, Malaysia. She was a fellow at Universiti Sains Malayisa. After graduating, she worked as senior lecturer at Faculty of Civil Engineering, Universiti Teknologi MARA, Pulau Pinang, Malaysia and was promoted to Associate Professor on 2017. Her research interest is Computational Mechanics, Computational Analysis of Shell and Spatial Structures, Nonlinear Analysis, Engineering Education and Architectural Engineering. She is also certified as an 'International Professional Engineer', 'APEC Engineer', 'ASEAN Engineer', Professional Engineer with Practising Certificate of Board of Engineers Malaysia, Corporate Member of The Institution of Engineers Malaysia, The ASEAN Federation of Engineering Organisations, Construction Industry Development Board Malaysia and Concrete Society of Malaysia. She is a Professional Engineer Interviewer/Examiner for The Institution of Engineers Malaysia since 2016. Associate Professor Ir. Dr. Yee Hooi Min has obtained 16 awards in Invention, Innovation and Research Design Platform and has published 86 up-to-date publications. Her other achievements include invitations as Keynote Speaker, International Invited Speaker, International Visiting Professor, Session Chairman and technical committee to over international and national technical conferences and seminars worldwide which include those in Czech Republic, United Kingdom, Ireland, Spain, Australia, Republic of China, Indonesia, Thailand and Malaysia.

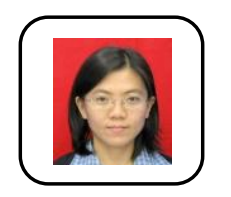

and pavement.

Dr. Li-Sian Tey is a Senior Lecturer in the Faculty of Civil Engineering at the Universiti Teknologi MARA, Cawangan Pulau Pinang. Her academic and research work focuses on transportation engineering, human factors, traffic safety, traffic modelling and simulation

\footnotetext{
pavement.
}

facto 